\title{
Airway response to exercise and methacholine in children with respiratory symptoms
}

\author{
J B Clough, S A Hutchinson, J D Williams, S T Holgate
}

\begin{abstract}
Thirty atopic and 30 non-atopic subjects were identified from a population of 7-8 year old children with current respiratory symptoms. The response of the airways to exercise and provocation by methacholine were compared. In these children, who had symptoms but were not necessarily asthmatic, there was no significant correlation between the two stimuli. The atopic children were, however, significantly more responsive than the nonatopic children to both. For the whole group, odds ratios derived for atopy and for an increased response to methacholine (expressed as a $\mathbf{P D}_{20}$ - the dose that caused the forced expiratory volume in one second $\left(F E V_{1}\right)$ to fall by $20 \%$ of $<6.4 \mu \mathrm{mol} / \mathrm{l}$ ), a positive exercise test $(>15 \%$ fall in FEV $)$, and the presence of asthma were $13.5,3 \cdot 3$, and $21 \cdot 0$, respectively; that for positive response to methacholine and positive exercise challenge was $1 \cdot 5$. Thus though increased bronchial responsiveness to methacholine and exercise challenge are both associated with a diagnosis of asthma, the association between the two stimuli is complex, and supports the view that they reflect entirely different components of airways dysfunction.
\end{abstract}

There is no universally accepted definition of asthma, although it is usually described clinically as reversible airways obstruction. Increasingly the word 'asthma' is used to embrace a range of diseases with the common end points of increased airways resistance and increased bronchial responsiveness. Establishing a diagnosis of asthma purely on clinical grounds can be difficult. There are no symptoms that are specific for asthma, especially in childhood when recurrent cough-particularly at nightis common. Attempts to delineate symptom complexes that are more specific for 'asthma' than single symptoms have not been successful. ${ }^{1}$ The recognition that enhanced responsiveness of the airways to various different stimuli often accompanied established asthma raised the possibility that a formal assessment of this component of airways dysfunction by provocation testing might provide the objective measurement that would enable the diagnosis of asthma to be made with a greater degree of certainty. Though increased bronchial responsiveness is a useful adjunct to the diagnostic profile of asthma, at any given moment only two thirds of clinically diagnosed asthmatic subjects respond in this way and up to one third of subjects with increased bronchial responsiveness have no symptoms. ${ }^{1-4}$ In addi- tion, reductions in baseline airway calibre and indices of responsiveness are continuous variables, so before making a diagnosis of asthma based on these measurements, it is necessary to decide how much reversibility of airway calibre or increase in bronchial responsiveness equates with asthma, and to define a cut off point that differentiates normal from abnormal.

A clinical assessment of airway responsiveness in a patient presenting with respiratory symptoms but with normal or near normal basal pulmonary function may provide useful additional information. In adults it is most often measured using inhaled methacholine or histamine as the provoking stimulus, by challenge tests for which detailed protocols and limits of repeatability have been clearly defined. In children an exercise test is more commonly done as this form of challenge is better accepted by this age group, and perhaps has more clinical relevance because physical activity plays an important part in most children's lives. Indeed, exercise challenge forms part of the assessment of the child with respiratory symptoms in many outpatient clinics.

Few comparisons have been made between exercise and methacholine or histamine as the provoking stimulus in bronchial challenge, and those that have do not only lack standardisation of methods, making comparisons between studies difficult, but have also been conducted on highly selected 'stable' groups of asthmatic patients. $^{5-8}$ If two procedures are to be compared for their diagnostic potential, it is imperative that the studies be undertaken in the population in which the discriminant test is to be used.

In the present study we have assessed the relationship of increased bronchial reactivity to exercise and to methacholine challenge in a group of 7-8 year old children with recurrent respiratory symptoms who were identified from a normal population by questionnaire. In this way the subjects were chosen so that they best represented the clinician's dilemma-children who had respiratory symptoms that might or might not be caused by asthma. Tests of airway responsiveness to both exercise and methacholine were done to see if there was any association between them in children with symptoms. In addition, we examined the influence of atopy on the two indices of airway responsiveness in these children.

\section{Subjects and methods} SELECTION OF SUBJECTS

As part of a larger epidemiological study, the families of all 7 and 8 year old children reg- 
istered on the lists of 86 local general practitioners were sent a questionnaire about respiratory symptoms. The relevant questions were:

- Has your child had an attack of wheezing at any time during the last 12 months?

- In the last 12 months, has your child seemed to cough more (or to get more coughs) than other children?

- In the last 12 months, has your child woken at night coughing for three or more consecutive nights (apart from during the first five days of a cold)?

A randomly selected sample of the symptomatic subjects was invited to join this study. The families were approached by telephone, or by a letter that included a reply slip and postage paid envelope. Reminder letters were sent after four weeks if no reply had been received. The study was approved by the Southampton hospitals and university ethics committee.

\section{METHODS}

Appointments were made for the families to attend the laboratory at the same time of day on two consecutive days. All appointments were outside school hours at times convenient for the families. On arrival the parent of each child was asked if they thought their child had asthma, whether their general practitioner had ever diagnosed asthma, and if their child was currently receiving any antiasthma medication. If the answer to the first or second and third questions was 'yes', the child was accepted as having asthma.

Each child underwent three investigations: (i) Allergen skin prick testing

A drug history was taken to ensure that no child was using any preparation that might interfere with a response. Skin prick tests to histamine (1 $\mathrm{mg} / \mathrm{ml}$ ), saline, Dermatophagoides pteronyssinus, mixed grass pollens, and cat fur (Bencard) were carried out. Standardised $1 \mathrm{~mm}$ spring loaded lancets were used to break the skin. Extracts were blotted after one minute, and the maximum diameter of the resulting weals was measured after 10 minutes. A weal $2 \mathrm{~mm}$ in diameter or more to one or more of the three common allergens was taken as a positive response. In addition all children were required to have a negative response to saline and a positive response to histamine.

On completing the skin tests, the first 30 children with positive reactions and the first 30 with negative reactions went on to be challenged with exercise and with methacholine. Of these 60 children 24 were diagnosed as having asthma; all 24 receiving $\beta_{2}$ adrenoceptor agonists, 21 by inhalation and three orally. In addition, three of the asthmatic children were receiving sodium cromoglycate, two were inhaling corticosteroids, and one was taking theophylline orally.

The two bronchial provocation tests were done in random order so that half the subjects underwent methacholine challenge first, and the other half had the exercise challenge first. The two tests were done on consecutive days at the same time of day by the same investigator.

(ii) Methacholine bronchial challenge

Children were asked not to use their $\beta_{2}$ adreno- ceptor agonists for six hours before each test. All other medication was withheld for 24 hours.

Methacholine challenge was done by the method described by Yan et al. ${ }^{9}$ The method was modified in the following ways: De Vilbiss 40 hand held glass nebulisers with known consistent outputs were selected by measuring the outputs of 10 nebulisers containing $1 \mathrm{ml} 0.9 \%$ sodium chloride by weighing them before and after 10 activations; this was repeated 10 times. For each nebuliser the mean output and the coefficient of variation was calculated. The five nebulisers with the smallest coefficients were used in the subsequent challenges.

Solutions of methacholine in $0.9 \%$ sodium chloride were made up for each nebuliser taking into account the mean output of each instrument so that the first delivered exactly 0.025 $\mu \mathrm{mol}$, the second $0 \cdot 1 \mu \mathrm{mol}$, the third $0 \cdot 4 \mu \mathrm{mol}$, and the fourth $0.8 \mu \mathrm{mol} /$ activation. The remaining nebuliser was used to give $0.9 \%$ sodium chloride.

At the first visit, forced expiratory volume in one second $\left(\mathrm{FEV}_{1}\right)$ was measured to obtain two baseline readings within $100 \mathrm{ml}$ of each other. If these exceeded $60 \%$ of the predicted for height and age, the challenged proceeded. The children were instructed in the use of the nebulisers. Once the investigator was satisfied that the child could carry out the procedure correctly, two puffs of saline were given and the $\mathrm{FEV}_{1}$ was measured one minute later. Provided that the child's $\mathrm{FEV}_{1}$ did not fall by more than $10 \%$ of the baseline value, the procedure was repeated using incremental doubling doses of methacholine from $0.025 \mu \mathrm{mol}$ to $6.4 \mu \mathrm{mol}$, until either the $\mathrm{FEV}_{1}$ fell by more than $20 \%$ of the baseline value, or the final dose was reached. The percentage fall in $\mathrm{FEV}_{1}$ measured after the saline had been given was plotted against the cumulative dose of methacholine on a log scale. The dose of methacholine that caused a $20 \%$ fall in $\mathrm{FEV}_{1}\left(\mathrm{PD}_{20}\right)$ was derived from linear interpolation of the last two points. For subjects in whom they lay between 6.4 and $12 \cdot 8 \mu \mathrm{mol}, \mathrm{PD}_{20}$ values were calculated by extrapolation. On completing the challenge, $100 \mu \mathrm{g}$ of salbutamol was given by inhalation from a spacer device to restore airway calibre.

\section{(iii) Exercise challenge}

Children were allowed to proceed to exercise challenge if their $\mathrm{FEV}_{1}$ was more than $60 \%$ of the predicted normal. The exercise challenge comprised treadmill running on a Powerjog treadmill (Sport Engineering), which was programmed to operate at a speed of $4.8 \mathrm{kph}$ and a gradient of $15^{\circ}$. The children exercised for six minutes. Their heart rates were measured with a three electrode yoke and cardiorater (Cardiac Recorders Ltd) to ensure that all subjects exercised to $90 \%$ of their age predicted maximum heart rate. Temperature in the exercise laboratory was kept between 22 and $24^{\circ} \mathrm{C}$. On completion of the exercise $\mathrm{FEV}_{1}$ was measured at 3, 5, and 10 minutes. Salbutamol $100 \mu \mathrm{g}$ was then given by a spacer device. The airways response to exercise was plotted as the percentage fall in $\mathrm{FEV}_{1}$ from baseline against time, and the max- 
imum fall within the 10 minute period was used for analysis.

\section{STATISTICAL METHODS}

The number required to give a correlation coefficient of 0.5 at the $5 \%$ level of significance was calculated. Thirty pairs of observations were shown to be adequate to do this with $80 \%$ power.

Because of the need to include censored values, and the skewed distribution of the values for the non-atopic subjects, nonparametric tests were used throughout. Spearman's rank correlation was used to examine the association between methacholine and exercise challenges separately for the atopic and the nonatopic children. In addition, the association between a positive methacholine challenge $\left(\mathrm{PD}_{20}<6.4 \mu \mathrm{mol}\right)$ and a positive exercise challenge (maximum fall in $\mathrm{FEV}_{1}$ after exercise $<15 \%$ ) was examined and odds ratios were calculated. These arbitrary cut off points were chosen because they were most commonly used by other workers. ${ }^{10-14}$ The specificity and sensitivity of each of the two challenges for detecting asthma were calculated. The Mann-Whitney U test was used to compared the responses of the atopic and non-atopic children for each challenge. 95\% Confidence intervals (CI) were calulated where appropriate.

\section{Results}

Of those initially approached, $89 \%$ of parents allowed their children to be investigated. Two children were unable to do technically adequate $\mathrm{FEV}_{1}$ tests; they were both small girls, who reached their forced vital capacity in less than one second, and so were excluded from further testing.

The results were analysed for 30 atopic and 30 non-atopic children, all of whom completed both challenge tests. The ratio of boys to girls between the atopic and non-atopic groups was

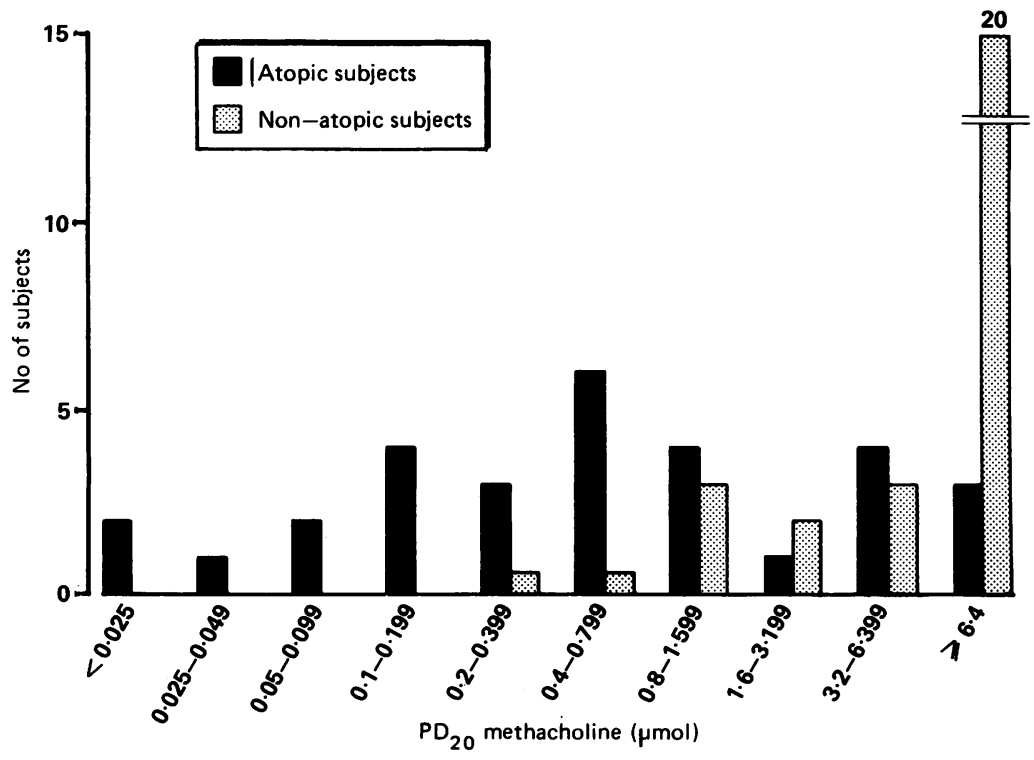

Figure 1 Response of atopic and non-atopic subjects to methacholine.
5:1 and $1: 1 \cdot 3$, respectively. The excess of boys in the atopic group was a result of the increased interest in sport among boys of this age compared with girls; the initial approach stressed the exercise content of the study, and boys were not only more likely to have had exercise induced bronchospasm because of their regular participation in team sports, but were also more willing to do the required tests. In addition, the increased proportion of boys in this study reflects the increased incidence of respiratory symptoms and asthma in this age group.

\section{METHACHOLINE PROVOCATION}

The atopic subjects were significantly more responsive to inhaled methacholine than those who had negative skin tests (fig 1). Of the 30 atopic children, only three had a $\mathrm{PD}_{20}>6.4$ $\mu \mathrm{mol}$, compared with 20 of those who were nonatopic. The median $\mathrm{PD}_{20}$ for the atopic group was $0.55 \mu \mathrm{mol}$ whereas that for the non-atopic group was $>12 \cdot 8 \mu \mathrm{mol}$, the difference being highly significant $(\mathrm{p}<0.001)$. The odds ratios for the association between atopy and a positive methacholine challenge was $13.5 \quad(p<0.001$, $95 \%$ CI $3 \cdot 3$ to $54 \cdot 7$ ).

\section{EXERCISE PROVOCATION}

The atopic children also showed a greater response to exercise than those who were nonatopic (fig 2). Ten of the 30 atopic children achieved a fall in $\mathrm{FEV}_{1}$ of $>15 \%$ after exercise compared with only four of those who were non-atopic. The median fall in $\mathrm{FEV}_{1}$ was $\mathbf{9 . 9 \%}$ for the atopic children and $4.8 \%$ for the nonatopic children, the difference being significant $(p=0.02,95 \%$ CI 1.3 to $14 \cdot 2)$. The odds ratio for the association between atopy and a positive exercise challenge was $3 \cdot 3(p=0 \cdot 13,95 \%$ CI $0 \cdot 9$ to $11 \cdot 9$ ).

Of the 24 subjects with diagnosed asthma, 21 were atopic and the odds ratio for the association between atopy and asthma was $21 \cdot 0$ $(\mathrm{p}<0.001,95 \%$ CI 5.0 to $87 \cdot 4)$. Twenty achieved a $\mathrm{PD}_{20}$ of methacholine of $<6.4 \mu \mathrm{mol}$ (fig 3). Of these, seven responded to exercise

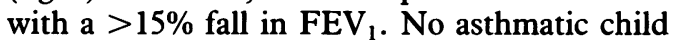

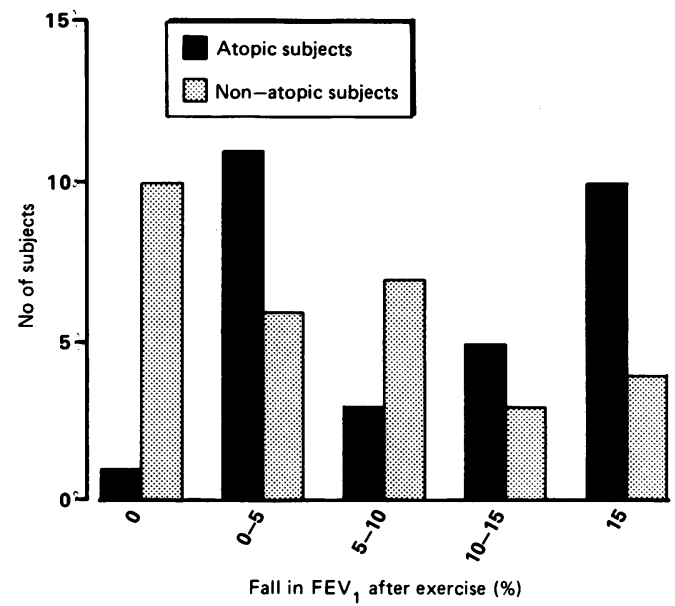

Figure 2 Response of atopic and non-atopic subjects to exercise. 


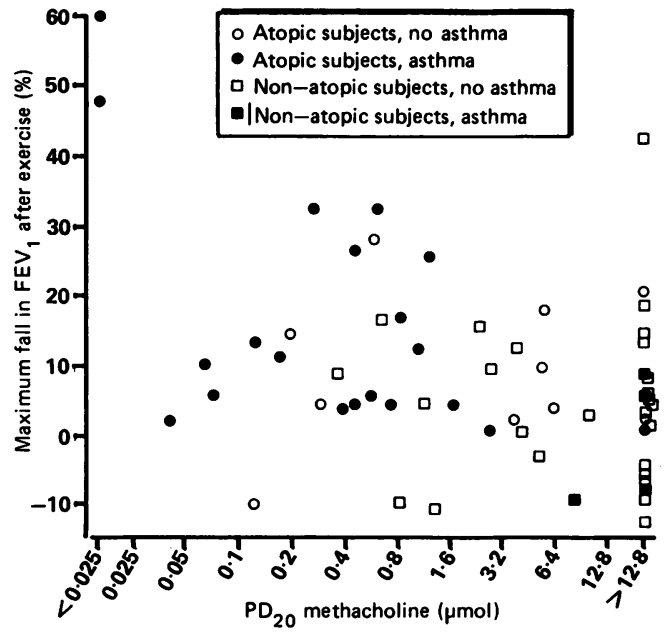

Figure 3 Maximum percentage fall in $F E V_{1}$ after exercise plotted against $P D_{20}$ methacholine ( $\left.\mu \mathrm{mol}\right)$ for atopic and non-atopic subjects divided according to whether or not they had asthma.

responded to exercise alone. Of the 36 remaining subjects, 19 achieved a $\mathbf{P D}_{20}$ of methacholine of $<6.4 \mu \mathrm{mol}$, and of these, three also responded to exercise. In this group, four children responded to exercise alone with a $>15 \%$ fall in $\mathrm{FEV}_{1}$. The sensitivity of methacholine challenge was $83 \%$ and the specificity $47 \%$. The sensitivity of exercise challenge was $29 \%$ and the specificity $81 \%$.

\section{ASSOCIATION BETWEEN METHACHOLINE AND EXERCISE CHALLENGE}

Figure 3 shows the association between the results of exercise and methacholine challenge testing. When testing the association between exercise and methacholine, the Spearman rank correlation gave $r_{s}=0.04(p=0.84)$ for the atopic group and $r_{s}=0.26(p=0 \cdot 17)$ for the non-atopic group. Thus in neither group was there evidence to support the existence of an association significant at the $5 \%$ level. These results were supported by calculation of odds ratios for individual subjects who had both positive exercise and methacholine challenges; the odds ratio for the atopic group was $1.0(95 \% \mathrm{CI} 0.1$ to $12 \cdot 6)$ and for the non-atopic group $1.6(95 \% \mathrm{CI} 0.2$ to 13.2).

\section{Discussion}

In a group of children with recurrent respiratory symptoms we could find no significant correlation at the $5 \%$ level between the response of the bronchi either to inhaled methacholine or to exercise, although the children with positive skin tests were significantly more sensitive to both stimuli.

This does not support the findings of other studies, which have shown an association between the results of the two challenges. ${ }^{6} 8$ Previous studies, however, have studied groups with stable mild or moderate asthma and normal subjects. The group of children that we have studied consisted of subjects with symp- toms, but they were not preselected because of a diagnosis of asthma.

We made every attempt to exclude as many factors as possible that might have a confounding influence on the testing procedure. All testing was performed by the same investigator; the order of the two challenge procedures was randomised; the two tests were done at the same time of day to avoid any circadian effect on bronchial reactivity, and on consecutive days to minimise the effect of any changes resulting from exposure to allergens or viral infection; all testing was done before the pollen season; and measures were taken to ensure maximum effort in carrying out the $\mathrm{FEV}_{1}$-readings were repeated until two technically adequate recordings within $100 \mathrm{ml}$ of one another were obtained.

In common with other published reports on exercise challenge a single period of exercise was undertaken. ${ }^{5-7}$ This was in contrast to the way in which methacholine was given; we chose to give it in cumulative, incremental doses, as this is standard procedure in our department and we have done more than 2000 such challenges in young children without incident. An alternative would have been to predetermine the $\mathrm{PD}_{20}$ of methacholine and then to have given that dose as a single inhalation, but airway responsiveness can vary significantly over short periods of time, and so for reasons of safety and to enable us to compare two methods of bronchial challenge in current use, we preferred to deliver cumulative doses of methacholine.

A $\mathrm{PD}_{20}$ of $<6.4 \mu \mathrm{mol}$ methacholine was regarded as representing a positive challenge. Although any level of airway responsiveness that is chosen to represent the cut off between 'normal' and 'abnormal' in a group in which responsiveness to methacholine is a normally distributed phenomenon will of necessity be arbitrary, the definition of increased bronchial responsiveness used in this study $\left(\mathrm{PD}_{20}<6.4\right.$ $\mu \mathrm{mol})$ is widely used, ${ }^{1-9}$ and our conclusions would not have differed if $<12.8 \mu \mathrm{mol}$ had been taken as the cut off point.

The standardisation of exercise challenge is not easy. In this study we ensured that the degree of exercise was enough to cause an increase in heart rate to $>90 \%$ of the age predicted maximum in all subjects. Pulmonary function testing was not done during exercise as the use of a mouthpiece and nose clip was unacceptable to the children. Though these are regarded as standard in exercise challenge tests in adults-both to ensure mouth breathing and to allow investigation of the expired gases-this is not the case in paediatric practice. A review of the other studies available ${ }^{10-14}$ showed that none had used nose clips; that various types of exercise were used that are inferior to treadmill running ${ }^{1011} 13$; and though most ensured that heart rate did increase to a preselected percentage of the age predicted maximum at some time during exercise, ${ }^{12-14}$ some failed to monitor heart rate in half ${ }^{10}$ or all ${ }^{11}$ subjects. Warm air represents a less potent stimulus to the bronchial tree than cold air, and the temperature in our exercise laboratory was $22-24^{\circ} \mathrm{C}$. This may explain our relatively low incidence of exercise 
induced bronchospasm compared with the $63-71 \%$ found in other studies done on children of similar age. This finding might, however, be a reflection of selection; children selected from a community based survey are likely to have less severe symptoms than those attending hospital.

Exercise induced bronchospasm is not an invariable feature of asthma, nor is it exclusive to asthma. It can occur in conjunction with cystic fibrosis, ${ }^{15}$ with a history of previous asthma, ${ }^{16}$ and in normal subjects. ${ }^{11} 12$ Konig and Godfrey have, however, shown that there is an increased prevalence in the relatives of asthmatic subjects, ${ }^{17}{ }^{18}$ and a higher concordance between pairs of monozygotic twins compared with dizygotic twins. ${ }^{19}$ This suggests that it is an inherited phenomenon, and is inherited independently of atopy. In view of the established genetic association between atopy and asthma, ${ }^{20}$ and that between asthma and exercise induced bronchospasm, it is not surprising that it was over three times more common in atopic than in non-atopic children. The question is therefore: what disease is causing the bronchospasm, the reaction to methacholine and the respiratory symptoms in the non-atopic children? Asthma is a clinical syndrome, and as such may represent a range of diseases with different causes. Within that range there may be a subgroup of children without atopy who demonstrate symptoms only when provoked by specific stimuli such as viral respiratory tract infections. ${ }^{21}$ It has been suggested that children with such symptoms may lose them as they become older because atopy is necessary for symptoms to persist into adult life. Although viral respiratory infections may be the primary stimulus in these children, they may also be more susceptible to other respiratory stimuli, both specific and non-specific.

We have failed to show a significant association between exercise induced and methacholine responsiveness, both when the complete data were examined, and when 'positive' responses alone were analysed. This might have been because of the heterogeneity of the study group and, indeed, the studies that have shown such an association have usually preselected their subjects. The relatively poor reproducibility of exercise challenge testing may also be a contributory factor. ${ }^{22}$

An alternative explanation lies in the mode of action of the stimuli used, as different stimuli may act through different bronchoconstricting mechanisms. Pauwels et al have suggested that the term 'non-specific' when applied to increased bronchial responsiveness is no longer adequate to cover both the pharmacological and the physical stimuli that can result in an increased bronchoconstrictor response of the airways. ${ }^{23}$ They suggested that a distinction should be made between those non-specific stimuli that act directly on the smooth muscle, of the airways and those that affect structures other than the smooth muscle, such as mast cells and neurones. The examples they cited were exercise, adenosine, and neurokinin A, and they suggested that these types of stimuli should be designated 'direct' and 'indirect'. Testing with both types of stimuli might perhaps be of use in clinical practice, but the results of such testing must be interpreted in the light of the increasing evidence of their lack of specificity in diagnosing asthma. It could be argued that exercise testing should be preferred to chemical stimuli because of its environmental relevance.

These results emphasise that exercise induced bronchospasm is not simply an index of nonspecific bronchial responsiveness. Asthma is a complex group of heterogeneous diseases, and care must be taken when interpreting the results of studies in which the subjects were selected to represent a single facet of the disease. Using different stimuli to challenge the airways will supply different answers, and as Pauwels et al suggest, the use of both 'direct' and 'indirect' stimuli in longitudinal epidemiological studies of bronchial responsiveness will shed more light on both the pathogenesis of asthma and the relevance of bronchial responsiveness.

1 Burney PGJ, Britton WJ, Chin S, Tattersfield AE, Papacosta AO. Descriptive epidemiology of bronchial reactivity in an adult population; results from a community survey. Thorax 1987;42:38-44.

2 Sears MR, Jones DT, Holdaway MD. Prevalence of bronchial reactivity to inhaled methacholine in New Zealand children. Thorax 1986;41:283-9.

3 Salome CM, Peat JK, Britton WJ. Bronchial hyperresponsiveness in two populations of Australian schoolchildren: I. relation to respiratory symptoms and diagnosed asthma. Clinical Allergy 1987;17:271-82.

4 Hopp RJ, Bewtra AK, Nair NM, Watt GD, Townley RG. Methacholine inhalation challenge studies in a selected paediatric population. Am Rev Respir Dis 1986;134:994-8.

Chatham M, Bleeker ER, Smith PL. A comparison of histamine, methacholine and exercise airway reactivity in 126:235-40.

6 Kiviloog J. Bronchial reactivity to exercise and methacholine in bronchial asthma. Scandinavian fournal of Respiratory Disease 1973;54:347-58.

7 Anderton RC, Cuff MT, Frith PA, et al. Bronchial responsiveness to inhaled histamine and exercise. $\mathcal{F}$ Allergy Clin Immunol 1979;63:315-20.

8 Eggleston PA. A comparison of the asthmatic response to methacholine and exercise. F Allergy Clin Immunol 1979;63: 104-10.

9 Yan K, Salome C, Woolcock A. Rapid method for measurement of bronchial responsiveness. Thorax 1983;38:1-5.

10 Tsanakas JN, Milner RDG, Bannister OM, Boon AW. Free running asthma screening test. Arch Dis Child 1988;63: running.

11 Kawabori I, Pierson WE, Conquest LL, Bierman CW. Incidence of exercise-induced asthma in children. $\mathcal{F}$ Allergy Clin Immunol 1976;58:447-55.

12 Kattan M, Keens TG, Mellis CM. The response to exercise in normal and asthmatic children. $\mathcal{F}$ Pediatr 1978;92:718-21.

13 Cropp GJA. Grading, time-course and incidence of exercise induced airway obstruction and hyperinflation in asthmatic children. Pediatrics 1975;56:868-9.

14 Mellis CM, Kattan M, Keens TG, Levison H. Comparative studies of histamine and exercise challenges in asthmatic children. Am Rev Respir Dis 1978;117:911-5.

15 Mellis CM, Lenson H. Bronchial reactivity in cystic fibrosis. Pediatrics 1978;61:446-50.

16 Blackhall MI. Ventilatory function in subjects with childhood asthma who have become symptom-free. Arch Dis Child
1970;45:363-6.

17 Konig P, Godfrey S. Prevalence of exercise-induced bronchial lability in families of children with asthma. Arch Dis Child 1973;48:513-8.

18 Konig P, Godfrey S. Exercise-induced bronchial lability and atopic status of families of infants with wheezy bronchitis. atopic status of families of infants
Arch $D$ is Child 1973;48:942-6.

19 Konig P, Godfrey S. Exercise-induced bronchial lability in monozygotic (indentical) and dizygotic (non-identical) twins. I Allergy Clin Immunol 1974;54:280-7.

20 Cookson WOCM, Musk AW, Ryan G. Associations between asthma history, atopy and non-specific bronchial respon siveness in young adults. Clinical Allergy 1986;16:425-32.

1 Clifford RC, Howell JB, Radford M, Holgate ST. Associations between respiratory symptoms, bronchial responsiveness to methacholine, and atopy in two age-groups of schoolchildren. Arch Dis Child 1989;64:1133-9.

22 Godfrey S, Silverman M, Anderson S. Problems of interpreting exercise-induced asthma. F Allergy Clin Immunol 1973; 52:199-209.

23 Pauwels R, Joos G, Van der Straeten M. Bronchial hyperresponsiveness is not bronchial hyper-responsiveness is not bronchial asthma. Clinical Allergy 1988;18:317-21. 